\title{
Lateral Displacement of Retaining Walls
}

\author{
José Medina, Nicolás Sau and Jesús Quintana \\ Department of Civil Engineer and Mining, University of Sonora, Hermosillo, Sonora 83000, México
}

\begin{abstract}
When Rankine or Coulomb theories to design of retaining wall are used, it is accepted beforehand that the retaining wall will experience a lateral displacement. This displacement is normally not calculated when a retaining wall is designed. This paper describes a method to estimate the lateral displacement of retaining walls. A practical example in the lateral displacement of a gravity retaining wall is presented.
\end{abstract}

Key words: Lateral displacement, retaining wall, passive earth thrust, active earth thrust, Rankine theory, Coulomb theory.

\section{Introduction}

When Rankine or Coulomb theories are used to design a retaining wall, it is accepted beforehand that the retaining wall will experience a lateral displacement. By allowing the wall to move laterally, the earth pressure decreases on the active side of the wall and earth pressure increases on the passive side, and therefore more economical walls can be obtained when the lateral displacement is allowed. This lateral displacement is usually not calculated when designing a retaining wall. This article describes a method that estimates the lateral displacement of retaining walls.

\section{Passive Side Reaction Equilibrium}

When the wall slides laterally the active earth thrust develops and the frictional strength is mobilized at the base of the wall. The reaction on the passive side is determined from the balance of forces in the horizontal direction, by the Eq. (1), Fig. 1:

$$
\mathrm{R}_{\mathrm{EH}}=\mathrm{E}_{\mathrm{AH}}-\mathrm{F}_{\mathrm{F}}
$$

where, $\mathrm{E}_{\mathrm{AH}}$ is the horizontal component of active earth thrust, $F_{F}$ is the friction force that develops at the base of the wall and $\mathrm{R}_{\mathrm{EH}}$ is the equilibrium reaction that takes place on the passive side of the wall.

Soil-retaining wall contact pressure on the passive side is obtained from Eq. (2):

Corresponding author: José Medina, M. Eng., professor, research field: foundation and geotechnical engineering. E-mail: jose.medina@prolas.com.mx.

$$
\mathrm{Q}_{\mathrm{E}}=\mathrm{R}_{\mathrm{EH}} / \mathrm{D}_{\mathrm{F}}
$$

where, $\mathrm{Q}_{\mathrm{E}}$ is soil-wall contact pressure on the passive side wall and $D_{F}$ is the depth of the retaining wall foundation.

\section{Calculation of the Lateral Displacement}

The lateral displacement of the retaining wall is obtained from Eq. (3), Zeevaert [1]:

$$
\delta \mathrm{h}=\sum_{\mathrm{i}=1}^{\mathrm{n}} \mathrm{M}_{\mathrm{hi}} \Delta \sigma_{\mathrm{hi}} \Delta \mathrm{x}
$$

where, $\delta \mathrm{h}$ is the lateral displacement of the retaining wall, $\mathrm{M}_{\mathrm{hi}}$ is the soil horizontal deformation module in section $\mathrm{i}, \Delta \mathrm{x}$ is the width of the sections considered, $\Delta \sigma_{\mathrm{hi}}$ is the increase in the horizontal stress at the center of section $\mathrm{i}$ and $\mathrm{n}$ is the number of sections considered in the calculation of the horizontal displacement (Fig. 2).

The increment in the horizontal stress, at the center of the retaining wall and at one half of $\mathrm{D}_{\mathrm{F}}$ is obtained with Eq. (4), Medina [2]:

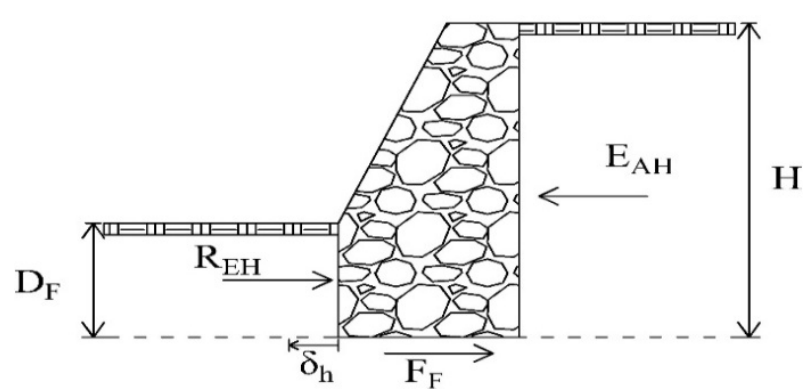

Fig. 1 Horizontal reaction on the passive side of the wall. 


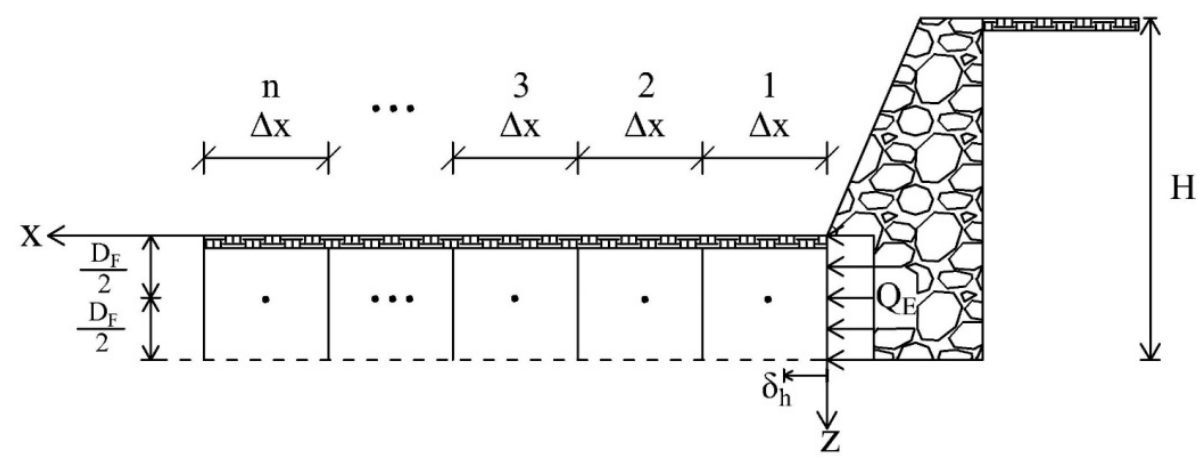

Fig. 2 Lateral displacement of the retaining wall.

$$
\begin{aligned}
& \Delta \sigma_{\mathrm{h}}=\mathrm{Q}_{\mathrm{E}} \mathrm{I}_{\mathrm{FH}} \\
& I_{\mathrm{FH}}=\frac{3 \mathrm{C} 1}{2 \pi}\left(\operatorname{sen} \alpha_{0}-\frac{\operatorname{sen}^{3} \alpha_{0}}{3}\right) \times\left\{\left(\psi_{1}-\psi_{2}\right)+\operatorname{sen}\left(\psi_{1}-\psi_{2}\right) \times \cos \left(\psi_{1}+\psi_{2}\right)\right\}+ \\
& \frac{3 C 2}{2 \pi}\left(\operatorname{sen} \alpha_{0}^{\prime}-\frac{\operatorname{sen}^{3} \alpha_{0}^{\prime}}{3}\right) \times\left\{\left(\psi_{1}^{\prime}-\psi_{2}^{\prime}\right)+\operatorname{sen}\left(\psi_{1}-\psi_{2}^{\prime}\right) \times \cos \left(\psi_{1}^{\prime}+\psi_{2}^{\prime}\right)\right\} \\
& \alpha_{0}=\tan ^{-1}\left\{\frac{\mathrm{L}}{2 \mathrm{x}}\right\} ; \psi_{1}=\tan ^{-1}\left\{\frac{\mathrm{D}_{\mathrm{F}}}{2 \mathrm{x}}\right\} ; \psi_{2}=\tan ^{-1}\left\{\frac{-\mathrm{D}_{\mathrm{F}}}{2 \mathrm{x}}\right\} \\
& \alpha_{0}^{\prime}=\tan ^{-1}\left\{\frac{\mathrm{L}}{2 \sqrt{\mathrm{D}_{\mathrm{F}}^{2}+\mathrm{x}^{2}}}\right\} ; \psi_{1}^{\prime}=\tan ^{-1}\left\{\frac{3 \mathrm{D}_{\mathrm{F}}}{2 \mathrm{x}}\right\} ; \psi_{2}^{\prime}=\tan ^{-1}\left\{\frac{\mathrm{D}_{\mathrm{F}}}{2 \mathrm{x}}\right\}
\end{aligned}
$$

where, $\Delta \sigma_{\mathrm{h}}$ is the increase in the horizontal stress, $\mathrm{I}_{\mathrm{FH}}$ is the influence value at the center of the retaining wall and at one half of $D_{F}, L$ is the retaining wall length, $x$ is the horizontal distance from the origin of the $\mathrm{X}$ axis to the center of the corresponding section (Fig. 2), C1 and $\mathrm{C} 2$ are coefficients depending on Poisson's ratio of the material and are obtained from Fig. 3.

\section{Example}

\subsection{Problem Statement}

For the retaining wall shown in Fig. 4, calculate:

(1) Lateral displacement at the center of the wall;

(2) Lateral displacement at the edge of the wall;

(3) Lateral displacement at the center of the wall for the passive earth thrust;
(4) Lateral displacement at the edge of the wall for the passive earth thrust.

Consider the following:

- $\mathrm{B}=3.40 \mathrm{~m}, \mathrm{~b}=2.20 \mathrm{~m}, \mathrm{H}=6.50 \mathrm{~m}, \mathrm{D}_{\mathrm{F}}=1.20 \mathrm{~m}$;

- Wall with vertical drain over an impervious material;

- Retaining wall with a unit weight of $21.60 \mathrm{kN} / \mathrm{m}^{3}$;

- Uniform overload, $\mathrm{q}=15 \mathrm{kN} / \mathrm{m}^{2}$;

- Unit weight of saturated soil, $\gamma \mathrm{msat}=20.85$ $\mathrm{kN} / \mathrm{m}^{3}$;

- Angle of internal friction of soil, $\varphi=36^{\circ}$;

- Soil cohesion, $\mathrm{C}=0 \mathrm{kN} / \mathrm{m}^{2}$;

- Soil Poisson's ratio, $v=0.30$;

- Soil-wall friction angle, $\delta=12^{\circ}$;

- Supporting soil-wall friction coefficient, $\mu=0.36$; 


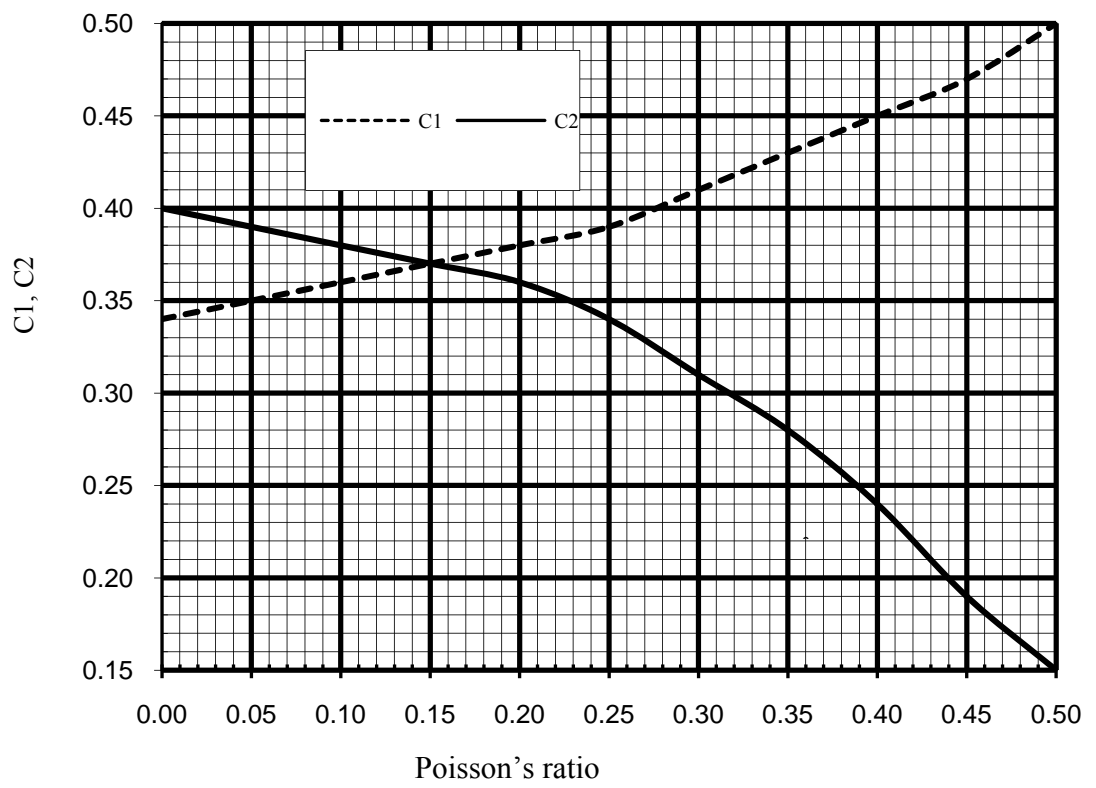

Fig. 3 Coefficients $\mathrm{C} 1$ and $\mathrm{C} 2$ as functions of the Poisson's ratio.

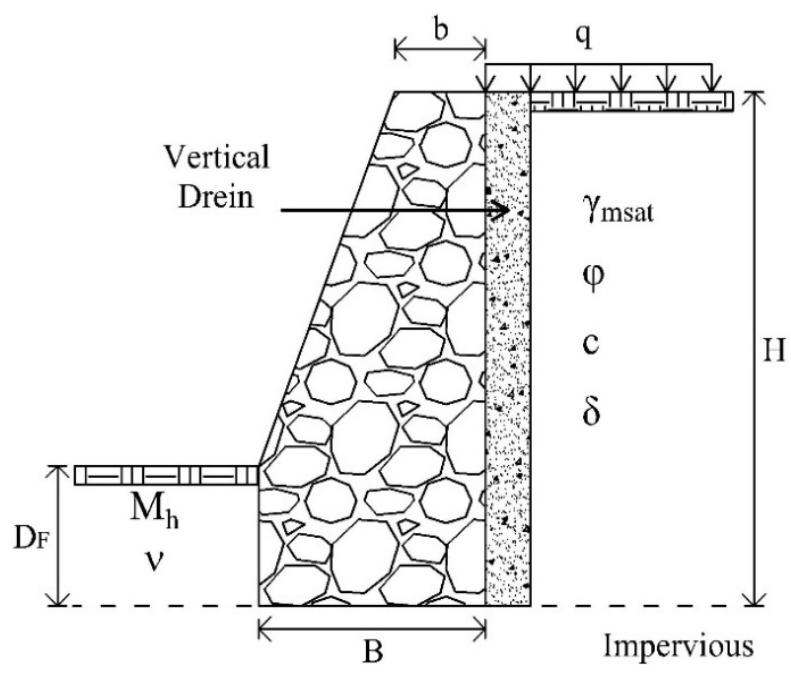

Fig. 4 Example retaining wall.

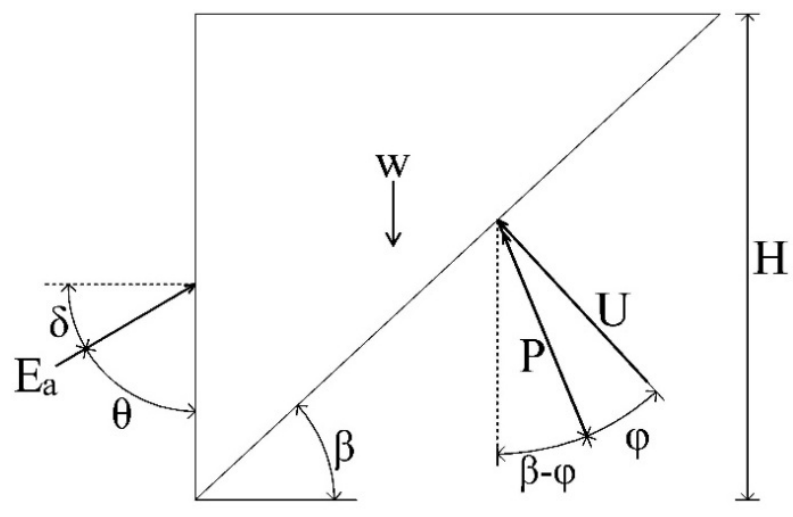

Fig. 5 Wedge free body diagram, active case.
- Soil deformation modulus, $\mathrm{M}_{\mathrm{h}}=0.0006 \mathrm{~m}^{2} / \mathrm{kN}$, considered constant;

- Retaining wall length, $\mathrm{L}=20 \mathrm{~m}$.

\subsection{Solution}

\subsubsection{Active Earth Thrust}

The earth thrust against the retaining wall, for the active case, is given by Eq. (8), Lambe and Whitman [3]:

$$
\mathrm{Ea}=\frac{(\mathrm{W}-\mathrm{U} \cos \beta) \tan (\beta-\varphi)+\mathrm{Usen} \beta}{\operatorname{sen} \theta+\tan (\beta-\varphi) \cos \theta}
$$

where, Ea is the earth thrust against the retaining wall for the active case, $\mathrm{W}$ is the weight of the wedge which includes the load $q$ on it, $U$ is the porewater force acting against the sliding surface, $\mathrm{P}$ is the resultant of the friction force on the failure plane and normal force on this plane, $\varphi$ is the angle of internal friction of soil, $\beta$ is the angle between the failure plane and the horizontal, and $\theta$ is the angle between the thrust Ea line of action and the vertical (Fig. 5).

The weight of the wedge plus the overload q on it, is obtained from Eq. (9):

$$
\mathrm{W}=\left[\frac{\gamma_{\mathrm{m}} \mathrm{H}}{2}+\mathrm{q}\right]\left(\frac{\mathrm{H}}{\tan \beta}\right)
$$


where, $\gamma_{\mathrm{m}}$ is the soil unit weight, $\mathrm{H}$ is the height of the retaining wall and $\mathrm{q}$ is the charge per unit area due to the overload acting above the active fill.

The porewater force $\mathrm{U}$ is obtained from Eq. (10), Medina et al. [4]:

$$
\mathrm{U}=\mathrm{k} \mathrm{H}^{2}
$$

where, $\mathrm{k}$ is a coefficient depending on the angle $\beta$ (Table 1).

Table 1 shows the calculation of active earth thrust against the retaining wall.

From Table 1, the active earth thrust, $\mathrm{E}_{\mathrm{A}}$ is:

$$
\mathrm{E}_{\mathrm{A}}=161.591 \mathrm{kN} / \mathrm{m}
$$

The horizontal component of the active thrust is:

$$
\mathrm{E}_{\mathrm{AH}}=\mathrm{E}_{\mathrm{A}} \cos \delta=158.059 \mathrm{kN} / \mathrm{m}
$$

\subsubsection{Passive Earth Thrust}

The earth thrust against the retaining wall, for the passive case, is given by Eq. (11) obtained from the balance of forces in the vertical and horizontal direction of the failure wedge shown in Fig. 6:

$$
E p=\frac{W \tan (\beta+\varphi)}{\operatorname{sen} \theta+\tan (\beta+\varphi) \cos \theta}
$$

Table 2 shows the calculation of passive earth thrust. From Table 2, the passive earth thrust, $\mathrm{E}_{\mathrm{P}}$ is:

$$
\mathrm{E}_{\mathrm{P}}=91.279 \mathrm{kN} / \mathrm{m}
$$

The horizontal component of the passive thrust is:

$$
\mathrm{E}_{\mathrm{PH}}=\mathrm{E}_{\mathrm{P}} \cos \delta=89.284 \mathrm{kN} / \mathrm{m}
$$

\subsubsection{Friction Force at the Base of the Wall}

The frictional force at the wall base is obtained from Eq. (12):

$$
\mathrm{F}_{\mathrm{F}}=\mu \mathrm{Wm}
$$

where, $\mathrm{F}_{\mathrm{F}}$ is the frictional force at the wall base, $\mathrm{Wm}$ is the weight of the wall and $\mu$ is the friction coefficient between the wall and the supporting soil.

$$
\begin{gathered}
\mathrm{Wm}=408.672 \mathrm{kN} / \mathrm{m} \\
\mathrm{F}_{\mathrm{F}}=147.122 \mathrm{kN} / \mathrm{m}
\end{gathered}
$$

\subsubsection{Equilibrium Reaction Passive Side}

The equilibrium reaction on the passive side of the wall is obtained from Eq. (1); and the soil-wall contact pressure on the passive side is obtained from Eq. (2):

$$
\begin{aligned}
\mathrm{R}_{\mathrm{EH}} & =10.938 \mathrm{kN} / \mathrm{m} ; \\
\mathrm{Q}_{\mathrm{E}} & =9.115 \mathrm{kN} / \mathrm{m}^{2}
\end{aligned}
$$

\subsubsection{Lateral Displacement at the Wall Center}

In the calculation of the lateral displacement, 8 sections of the same width, $\Delta \mathrm{x}=2.40 \mathrm{~m}$ were considered. Table 3 shows the calculation of the lateral displacement at the center of the retaining wall.

From Table 3, the lateral displacement at the center of the retaining wall is the following:

$$
\delta \mathrm{hc}=\sum_{\mathrm{i}=1}^{8} \Delta \delta \mathrm{hi}=0.90 \mathrm{~cm}
$$

Table 1 Calculation of active earth thrust.

\begin{tabular}{lllll}
\hline$\beta \mathrm{i}$ & $\mathrm{Wi}$ & $\mathrm{ki}$ & $\mathrm{Ui}$ & Eai \\
\hline$\left(^{\mathrm{o}}\right)$ & $(\mathrm{kN} / \mathrm{m})$ & $\left(\mathrm{kN} / \mathrm{m}^{3}\right)$ & $(\mathrm{kN} / \mathrm{m})$ & $(\mathrm{kN} / \mathrm{m})$ \\
\hline 53 & 405.379 & 1.657 & 70.021 & 160.289 \\
54 & 390.848 & 1.578 & 66.658 & 160.840 \\
55 & 376.681 & 1.496 & 63.207 & 160.987 \\
56 & 362.856 & 1.446 & 61.100 & 161.591 \\
57 & 349.353 & 1.367 & 57.753 & 161.127 \\
58 & 336.152 & 1.301 & 54.957 & 160.668 \\
59 & 323.237 & 1.266 & 53.468 & 160.678 \\
\hline
\end{tabular}

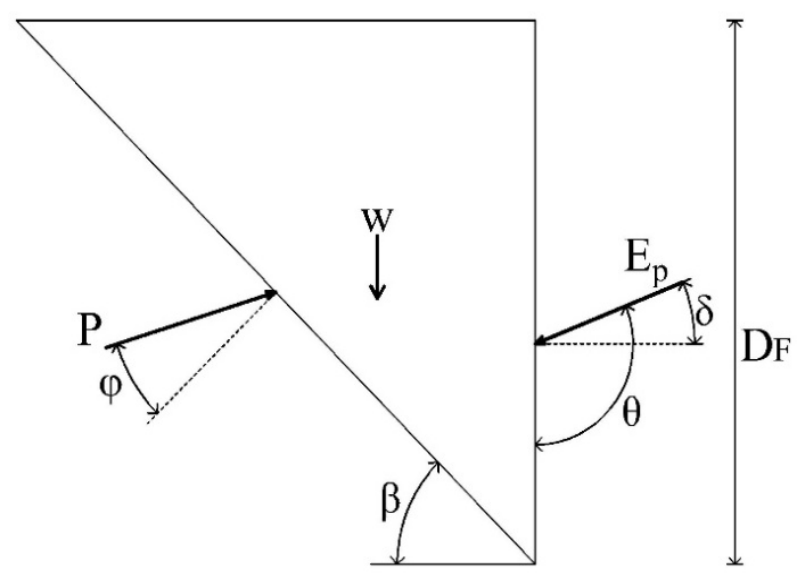

Fig. 6 Wedge free body diagram, passive case.

Table 2 Calculation of the passive earth thrust.

\begin{tabular}{lll}
\hline$\beta i$ & Wi & Epi \\
\hline$\left(^{\circ}\right)$ & $(\mathrm{kN} / \mathrm{m})$ & $(\mathrm{kN} / \mathrm{m})$ \\
\hline 17 & 49.102 & 92.790 \\
18 & 46.202 & 91.898 \\
19 & 43.598 & 91.401 \\
20 & 41.245 & 91.279 \\
21 & 39.108 & 91.522 \\
22 & 37.156 & 92.129 \\
23 & 35.366 & 93.113 \\
\hline
\end{tabular}


Table 3 Lateral displacement calculation at the center of the retaining wall.

\begin{tabular}{lllllllll}
\hline Section & 1 & 2 & 3 & 4 & 5 & 6 & 7 & 8 \\
\hline Xi $(\mathrm{m})$ & 1.2000 & 3.6000 & 6.0000 & 8.4000 & 10.8000 & 13.2000 & 15.6000 & 18.0000 \\
$\alpha_{0}$ (rad.) & 1.4514 & 1.2252 & 1.0304 & 0.8721 & 0.7470 & 0.6483 & 0.5700 & 0.5071 \\
$\psi_{1}$ (rad.) & 0.4636 & 0.1651 & 0.0997 & 0.0713 & 0.0555 & 0.0454 & 0.0384 & 0.0333 \\
$\psi_{2}$ (rad.) & -0.4636 & -0.1651 & -0.0997 & -0.0713 & -0.0555 & -0.0454 & -0.0384 & -0.0333 \\
$\alpha_{0}{ }^{\prime}$ (rad.) & 1.4027 & 1.2081 & 1.0217 & 0.8672 & 0.7439 & 0.6464 & 0.5687 & 0.5062 \\
$\psi_{1}{ }^{\prime}$ (rad.) & 0.9828 & 0.4636 & 0.2915 & 0.2111 & 0.1651 & 0.1355 & 0.1149 & 0.0997 \\
$\psi_{2}{ }^{\prime}($ rad. $)$ & 0.4636 & 0.1651 & 0.0997 & 0.0713 & 0.0555 & 0.0454 & 0.0384 & 0.0333 \\
$\mathrm{I}_{\mathrm{FH}}$ & $2.8269 \mathrm{E}-01$ & $1.3759 \mathrm{E}-01$ & $8.5547 \mathrm{E}-02$ & $5.9235 \mathrm{E}-02$ & $4.3334 \mathrm{E}-02$ & $3.2852 \mathrm{E}-02$ & $2.5598 \mathrm{E}-02$ & $2.0405 \mathrm{E}-02$ \\
$\Delta \sigma \mathrm{hi}\left(\mathrm{kN} / \mathrm{m}^{2}\right)$ & 2.5766 & 1.2541 & 0.7797 & 0.5399 & 0.3950 & 0.2994 & 0.2333 & 0.1860 \\
$\Delta \delta \mathrm{hi}(\mathrm{cm})$ & 0.3710 & 0.1806 & 0.1123 & 0.0777 & 0.0569 & 0.0431 & 0.0336 & 0.0268 \\
\hline
\end{tabular}

Table 4 Lateral displacement calculation at the center of a $40 \mathrm{~m}$ long wall.

\begin{tabular}{lllllllll}
\hline Section & 1 & 2 & 3 & 4 & 5 & 6 & 7 & 8 \\
\hline xi (m) & 1.200 & 3.600 & 6.000 & 8.400 & 10.800 & 13.200 & 15.600 & 18.000 \\
$\alpha_{0}$ (rad.) & 1.5109 & 1.3927 & 1.2793 & 1.1732 & 1.0757 & 0.9874 & 0.9084 & 0.8380 \\
$\psi_{1}$ (rad.) & 0.4636 & 0.1651 & 0.0997 & 0.0713 & 0.0555 & 0.0454 & 0.0384 & 0.0333 \\
$\psi_{2}$ (rad.) & -0.4636 & -0.1651 & -0.0997 & -0.0713 & -0.0555 & -0.0454 & -0.0384 & -0.0333 \\
$\alpha_{0}{ }^{\prime}$ (rad.) & 1.4861 & 1.3833 & 1.2739 & 1.1695 & 1.0731 & 0.9855 & 0.9069 & 0.8369 \\
$\psi_{1}^{\prime}($ rad.) & 0.9828 & 0.4636 & 0.2915 & 0.2111 & 0.1651 & 0.1355 & 0.1149 & 0.0997 \\
$\psi_{2}{ }^{\prime}($ rad.) & 0.4636 & 0.1651 & 0.0997 & 0.0713 & 0.0555 & 0.0454 & 0.0384 & 0.0333 \\
$\mathrm{I}_{\mathrm{FH}}$ & $2.8272 \mathrm{E}-01$ & $1.3830 \mathrm{E}-01$ & $8.7932 \mathrm{E}-02$ & $6.3580 \mathrm{E}-02$ & $4.9245 \mathrm{E}-02$ & $3.9711 \mathrm{E}-02$ & $3.2854 \mathrm{E}-02$ & $2.7663 \mathrm{E}-02$ \\
$\Delta \sigma \mathrm{hi}\left(\mathrm{kN} / \mathrm{m}^{2}\right)$ & 2.5769 & 1.2605 & 0.8015 & 0.5795 & 0.4488 & 0.3619 & 0.2994 & 0.2521 \\
$\Delta \delta$ hi $(\mathrm{cm})$ & 0.3711 & 0.1815 & 0.1154 & 0.0834 & 0.0646 & 0.0521 & 0.0431 & 0.0363 \\
\hline
\end{tabular}

4.2.6 Lateral Displacement at the Edge of the Wall

For the calculation of the lateral displacement on the edge of the retaining wall, first the lateral displacement is calculated in the middle of a wall twice as long; i.e. a wall of $40 \mathrm{~m}$ in length. In the calculation of the lateral displacement, 8 sections of the same width, $\Delta \mathrm{x}=2.40$ $\mathrm{m}$ were considered. Table 4 shows the calculation of the lateral displacement at the center of a 40 meters long wall.

From Table 4:

$$
\delta \mathrm{h}=\sum_{\mathrm{i}=1}^{8} \Delta \delta \mathrm{hi}=0.95 \mathrm{~cm}
$$

Therefore, the displacement on the edge of a $20 \mathrm{~m}$ length wall will be half the displacement at the center of a $40 \mathrm{~m}$ length wall:

$$
\text { Sho }=0.48 \mathrm{~cm}
$$

4.2.7 Lateral Displacement at the Middle due to Passive Thrust

The lateral displacement at the edge of the wall for the passive earth thrust, is obtained from Eq. (13):

$$
\delta h c p=\delta h c \frac{E_{\mathrm{PH}}}{\mathrm{R}_{\mathrm{EH}}}
$$

$\mathrm{E}_{\mathrm{PH}}$ is the horizontal component of passive earth thrust, i.e.:

$$
\mathrm{E}_{\mathrm{PH}}=\mathrm{E}_{\mathrm{P}} \cos \delta=89.284 \mathrm{kN} / \mathrm{m}
$$

From Eq. (13):

$$
\delta \mathrm{hcp}=7.36 \mathrm{~cm}
$$

4.2.8 Lateral Displacement at the Edge due to Passive Earth Thrust

The lateral displacement on the edge of the retaining wall for a contact pressure equal to that provided by the passive thrust is obtained from Eq. (14):

$$
\delta \text { hop }=\delta \text { ho } \frac{E_{\mathrm{PH}}}{\mathrm{R}_{\mathrm{EH}}}
$$

From Eq. (14):

$$
\delta \text { hop }=3.87 \mathrm{~cm}
$$




\subsection{Discussion of Results}

The displacement on the edge of the retaining wall is about half the displacement at the center of the retaining wall.

The displacement at the center of a 40 m length wall is slightly larger than the displacement of a wall of 20 m long.

Considering the example discussed, the displacement of the retaining wall, for a contact pressure equal to that provided by the passive thrust, is approximately eight times greater than the lateral displacement of the wall for a contact pressure equal to that provided by the active thrust.

\section{Conclusions}

It is discussed a procedure for estimating the lateral displacement of a retaining wall, which is an aid to determine the dimensions B an b (Fig. 4) and depth of foundation for wall design.

When a retaining wall is designed, if the project permits, it is very convenient to design the wall so that it moves in a horizontal direction, decreasing the earth pressure on the active side and increasing the pressure of on the passive side, and therefore a more economic wall is obtained when lateral displacement is allowed.

As the wall moves in the horizontal direction, the earth pressure decreases on the active side and increases on the passive side, so that the balance of forces in the horizontal direction is reached.

\section{References}

[1] Zeevaert, L. 1983. Foundation Engineering for Difficult Subsoil Conditions. New York: Van Nostrand Reinhold Company.

[2] Medina, J. 2010. "Esfuerzo horizontal producido por una carga rectangular horizontal uniforme aplicada en el interior de un sólido." In Proceedings of XXV Reunión Nacional de la Sociedad Mexicana de Ingeniería Geotécnica 3: 871-6.

[3] Lambe, T. W., and Whitman, R. V. 1979. Soil Mechanics SI Version. New York: John Wiley \& Sons, Inc.

[4] Medina, J., and Mendoza, N. Sau y E. 2014. "Cálculo de la Fuerza de Presión del Agua en el Análisis de Muros de Contención.” XVIII Reunión nacional de Profesores de Ingeniería Geotécnica, Puerto Vallarta, Jalisco, México. 